\title{
Vozes que ecoam: racismo, violência e saúde da população negra
}

\author{
Raquel Rodrigues da Silva Barbosa ${ }^{1}$ \\ https://orcid.org/0000-0001-8872-8685
}

Cristiane Souza da Silva ${ }^{2}$

https://orcid.org/0000-0001-8209-102X

\author{
Arthur Alves Pereira Sousa ${ }^{3}$ \\ https://orcid.org/0000-0001-5646-2552
}

${ }^{1}$ Escola Fiocruz de Governo, Programa de Residência Multiprofissional em Atenção Básica, Brasília, DF, Brasil ${ }^{2}$ Escola Fiocruz de Governo, Programa de Residência Multiprofissional em Atenção Básica, Brasília, DF, Brasil ${ }^{3}$ Escola Fiocruz de Governo, Programa de Residência Multiprofissional em Atenção Básica, Brasília, DF, Brasil

\section{Vozes que ecoam: racismo, violência e saúde da população negra}

Resumo: Este artigo é um relato de experiência da implementação de um projeto denominado "ECOS: consciência, cor e saúde”, realizado em uma Unidade Básica de Saúde da região oeste do Distrito Federal, que teve como objetivo dialogar com profissionais de saúde e qualificar as ações junto à população negra que acessa o SUS. Inicialmente é feito um debate sobre as implicações da violência para a saúde e a correlação entre racismo e violência. Em seguida, discute-se sobre a importância da abordagem dessa temática na Atenção Básica. São resgatados dados sobre as iniquidades em saúde provocadas em decorrência do racismo e a importância de abordar essa temática no processo de formação de profissionais de saúde, ressaltando a centralidade da Política Nacional de Saúde Integral da População Negra. Por fim, relata-se a experiência obtida com o projeto, compreendendo que ele esteve inserido em um importante processo de rompimento de ciclos de violência racial. Palavras-chave: Racismo. Violência. Saúde.

\section{Echoing voices: racism, violence and black population's health}

Abstract: This article is an experience report about the implementation of a project called "ECOS: consciousness, color and health", carried out in a Basic Health Unit in the western region of the Federal District, which aimed to dialogue with health professionals and qualify the actions beside the black population that accesses the SUS. Initially, a debate about the implications of violence for health and the correlation between racism and violence is carried out. Then, the importance of addressing this theme in Primary Care is discussed. Data on the health inequalities caused by racism and the importance of addressing this issue in the process of training health professionals are retrieved, emphasizing the centrality of the National Policy of Integral Health of the Black Population. Finally, the experience obtained with the project is reported, understanding that it was inserted in an important process of breaking the cycles of racial violence.

Keywords: Racism. Violence. Health.

Recebido em 29.10.2020. Aprovado em 15.12.2020. Revisado em 13.02.2021.

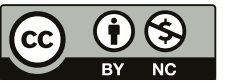

Este é um artigo publicado em acesso aberto (Open Access) sob a licença Creative Commons Attribution NonCommercial, que permite uso, distribuição e reprodução em qualquer meio, sem restrições desde que sem fins comerciais e que o trabalho original seja corretamente citado. 


\section{Introdução}

A violência é um fenômeno que atinge todas as sociedades desde sua formação, tendo diferentes formas de expressão e consequências para aqueles que a sofrem. Experiências de violência se manifestam e impactam grupos sociais de maneira diversa, e têm se mostrado devastadoras para populações socialmente marginalizadas, sendo infligidas, inclusive, pelo próprio Estado, que tendo a legitimidade do uso da força, a utiliza como forma de controle e manutenção de poder.

De acordo com a Organização Mundial da Saúde "a violência é definida como uso intencional da força física ou do poder, real ou em ameaça, contra si próprio, outra pessoa ou grupos e comunidades, que resulte ou tenha grande possibilidade de resultar em lesão, morte, dano psicológico, deficiência de desenvolvimento ou privação" (KRUG et al., 2002, p. 5). Nesse sentido, essa definição inclui atos que resultam de relações de poder, das quais o racismo se torna um elemento fundamental, tendo em vista que é consequência do estabelecimento de relações desiguais, nas quais a população preta, parda e indígena, no contexto brasileiro, ocupa posições socialmente marginalizadas. Neste artigo, compreende-se o racismo enquanto relação de poder tendo como base a violência social, material e simbólica, e que tem como consequências prejuízos na saúde física e psíquica de suas vítimas, dentre outras.

O racismo se manifesta de diversas formas, e a sociedade brasileira assume um quadro de desigualdades raciais em que brancos, negros e indígenas ocupam espaços diferentes na sociedade. Estudos demonstram que as populações negra e indígena brasileiras apresentam piores indicadores sociais, menores níveis de escolaridade e renda, menor acesso à saúde e vivem em condições mais precárias de moradia, porém a problemática do racismo ainda é socialmente invisibilizada, e esses dados são permanecem sendo analisados como consequências apenas da desigualdade econômica, ainda pouco considerando os aspectos raciais.

O racismo institucional é definido pelo Programa de Combate ao Racismo Institucional como o "fracasso coletivo de uma organização para prover um serviço apropriado e profissional para as pessoas por causa de sua cor, cultura ou origem étnica". (GELEDÉS et al., 2013, p. 11) Ele pode ser observado em atitudes e comportamentos de discriminação por preconceito, ignorância, negligência e estereotipação racista. Neste estudo, tem-se como foco o racismo contra a população negra brasileira.

Nos serviços de saúde, o racismo institucional pode ser observado na restrição ao acesso à saúde pela população negra, diferenças significativas no cuidado a doenças predominantemente negras, como, por exemplo a anemia falciforme, na qualidade da atenção à saúde e na falta de inclusão da questão racial na educação permanente dos profissionais. Vale ressaltar que um dos princípios básicos do SUS é a equidade, ou seja, os serviços de saúde devem ofertar tratamentos adequados e diferenciados, visando reduzir as vulnerabilidades sociais que, no caso da população negra, são causadas pelo processo histórico de exclusão social, econômica, política e cultural a que foi submetida.

Este artigo é um relato de experiência vivenciada por profissionais residentes de Serviço Social, Nutrição e Fisioterapia, inseridos em um programa de Residência Multiprofissional em Atenção Básica da Fundação Oswaldo Cruz (Fiocruz) de Brasília, durante atuação junto ao Núcleo Ampliado de Saúde da Família (NASF), de uma Unidade Básica de Saúde (UBS) da região oeste do Distrito Federal (DF). A residência multiprofissional se configura enquanto pós-graduação lato sensu, cujo enfoque é o ensino em serviço, ou seja, se constitui a partir da inserção de profissionais de nível superior em campos de atuação, de acordo com a área de cada programa no qual estão inseridos.

A partir da percepção de alguns profissionais da equipe de situações de racismo vivenciadas por outros profissionais e usuários do serviço, foi proposta uma ação interventiva, denominada "ECOS: consciência, cor e saúde", que teve como objetivo dialogar com os profissionais de saúde e qualificar as ações junto à população negra que acessa o SUS, dando visibilidade a questões relacionadas à formação social e econômica brasileira, ressaltando as diferenças estatísticas quando se relaciona dados entre negros e brancos, com enfoque para os serviços de saúde. A partir do reconhecimento de que o racismo produz marginalizações e interfere nos processos de saúde e adoecimento da população, é possível construir ofertas de cuidado pautados na integralidade desses sujeitos, conforme preconiza um dos princípios da Política Nacional de Atenção Básica (PNAB).

Este artigo está estruturado no formato de relato de experiência. Inicialmente é feita uma discussão sobre a relação entre racismo, violência e saúde. No segundo tópico, discute-se sobre a importância da abordagem dessa temática na Atenção Básica. No terceiro, são relatadas as iniquidades em saúde ocasionadas em 
decorrência do racismo e suas manifestações (individual, institucional e estrutural). Em seguida, é discutida sobre a importância de abordar esse tema na formação dos profissionais de saúde e o papel que a Política Nacional de Saúde Integral da População Negra (PNSIPN) desempenha nesse processo. Por fim, relata-se a experiência da implementação do projeto ECOS na unidade de saúde, relacionando-o à PNSIPN.

\section{Racismo, violência e as implicações para a saúde}

O racismo é definido por Almeida (2019, p. 37) em três esferas: individual, institucional e estrutural. No âmbito individual, ele é atribuído a grupos isolados, em situações isoladas, manifestando-se principalmente na forma de ações diretas. O racismo institucional é compreendido como resultado do funcionamento das instituições, que passam a atuar em uma dinâmica que confere desvantagens e privilégios com base na raça, demonstrando que o racismo é uma questão que extrapola as relações individuais. Assim, segundo o autor, o racismo pode ter sua forma alterada pela ação ou omissão dos poderes institucionais, como o Estado, escola, polícia, dentre outros. A concepção de racismo estrutural compreende, enfim, que o racismo decorre da própria estrutura social, ou seja, é consequência de como se constituem as relações políticas, econômicas, jurídicas e até familiares, tornando-se parte de uma conjuntura onde o racismo é regra, não exceção. Nesse sentido, o autor compreende que a mera presença de pessoas negras nas instituições não resolve a questão da discriminação racial, pois mesmo inseridos nelas, esses sujeitos permanecem suscetíveis a situações de racismo.

O Brasil é um dos países que mais mata, mas não mata aleatoriamente, observando-se um padrão nos dados sobre essas mortes. Segundo dados do Atlas da Violência de 2020, foram registradas 57.956 mortes violentas no Brasil em 2018, sendo que 75,7\% das vítimas eram negras, e as mulheres negras representam 68\% do total de mulheres assassinadas nesse período. O Atlas da Violência de 2018 ainda registra que a taxa de homicídio de jovens pretos e pardos é 2,5 vezes superior à de jovens brancos. Essas mortes atingem um grupo específico, e possuem recorte racial, porém não se analisa a violência racial do mesmo modo que se analisa a violência como um todo (CERQUEIRA et al., 2020). Compreende-se que a violência está ligada à estrutura que organiza as relações sociais, sendo reproduzida no cotidiano dos diversos grupos, especialmente no da juventude negra, portanto, o racismo deve ser compreendido a partir de sua conexão direta com a violência.

Chauí (1995, p. 432) afirma que "a violência é percebida como exercício da força física e da coação psíquica para obrigar alguém a fazer alguma coisa contrária a si, a seus interesses e desejos, ao seu corpo, sua consciência, causando danos profundos e irreparáveis, como a morte, a loucura, a autoagressão ou agressão aos outros". Segundo a autora, a violência é a violação da integridade física e psíquica e da dignidade humana de alguém.

Nesse mesmo sentido, Minayo (2004) considera a violência enquanto questão social, que deveria ser também objeto no setor saúde, devido, dentre outras questões, ao impacto que ela provoca na qualidade de vida, pelas lesões físicas, psíquicas e morais que acarreta e pelas exigências de atenção e cuidados dos serviços médico-hospitalares. A partir dos anos 90 a própria Organização Pan-Americana de Saúde (OPAS) e a Organização Mundial de Saúde (OMS) passaram a recomendar que os países membros incluíssem esse tema na sua agenda de intervenção.

Nota-se, no entanto, que esses debates dão maior ênfase à questão da violência quando a mesma é geradora de danos visíveis à saúde física, mencionando apenas brevemente os impactos da violência sobre a saúde psíquica dos sujeitos. Quando se debate os efeitos da violência racial sobre indivíduos negros, no entanto, é imprescindível que seja compreendido que ela afeta, além das condições materiais dos indivíduos, a sua saúde psíquica.

Santos (1983) analisa os impactos do racismo sobre o sofrimento psíquico da população negra. A autora afirma que falar de racismo implica em uma reflexão sobre a violência como núcleo central, pois "ser negro é ser violentado de forma constante, contínua e cruel, sem pausa ou repouso" (SANTOS, 1983, p. 2). A autora ressalta que o racismo, pela repressão ou persuasão, leva o sujeito negro a projetar um futuro identificatório que se mostra antagônico à realidade de seu corpo e sua história étnica e pessoal. É assim que o negro, no desejo de embranquecer, deseja, nada mais nada menos, sua própria extinção. Retomando então o pensamento de Chauí (1995), compreende-se que o racismo, quando reproduzido de forma explícita ou sutil, configura-se 
enquanto grave violência, tendo em vista que provoca danos profundos na integridade física, psíquica e na dignidade humana da população negra.

Almeida (2014) traduz a especificidade das relações raciais no Brasil no que ela denomina de 'racismo à brasileira', que, baseado no mito da democracia racial, reafirma preconceitos e práticas discriminatórias, ao passo que nega a existência de seus agentes, ou seja, reafirma-se, contraditoriamente, que o Brasil é um país racista, ao mesmo tempo que se nega que existam pessoas racistas no Brasil. É esse mito, ainda, responsável pela noção de que as desigualdades no Brasil não são causadas por fatores étnico-raciais, e refere-se apenas à classe social. De acordo com Almeida (2017), o mito da democracia racial contribui para a negação do racismo enquanto estrutura de poder e estratificação social, invisibiliza suas consequências e impede seu efetivo enfrentamento através de políticas públicas, como as de saúde, por exemplo. É necessário então, que o racismo seja compreendido como uma questão que deve ser abordada e enfrentada na agenda de saúde pública brasileira.

\section{A agenda da Atenção Básica}

O Sistema Único de Saúde (SUS) articula-se por meio das Redes de Atenção à Saúde (RAs), que são os arranjos organizativos de ações e serviços de saúde que buscam garantir o acesso universal dos cidadãos aos serviços de saúde e à integralidade do cuidado. Desse modo, é importante promover articulação das RAs com as necessidades de saúde da população negra, identificando as demandas e especificidades dessa população e reconhecer o racismo como um determinante social em saúde.

A Política Nacional de Saúde Integral da População Negra reconhece que o racismo institucional se configura em práticas que corroboram o aumento das desigualdades e colocam esses grupos raciais e étnicos em situação de desvantagem no acesso. No caso da saúde, a redução das iniquidades sociais é um dos objetivos do Pacto pela Saúde, que considera como determinantes e condicionantes de saúde os modos de vida, trabalho, habitação, ambiente, educação, lazer, cultura, acesso a bens e serviços essenciais, entre outros.

O Ministério da Saúde (BRASIL, 2017a) compreende que situações de desigualdades e vulnerabilidades afetam a saúde da população negra, como a precocidade dos óbitos, altas taxas de mortalidade materna e infantil, maior prevalência de doenças crônicas e infecciosas e altos índices de violência, e reconhece que o racismo vivenciado pela população negra incide negativamente nestes indicadores, comprometendo o acesso dessa população aos serviços públicos de saúde.

Segundo dados do Instituto de Pesquisa Econômica Aplicada (IPEA), publicados no Relatório Retrato das Desigualdades de Gênero e Raça em 2011, dos atendimentos ofertados pelo Sistema Único de Saúde (SUS), a população negra representa $67 \%$, e a branca, $47,2 \%$ do público total atendido. Da mesma forma, a maior parte dos atendimentos se concentra em usuários/as com faixa de renda entre um quarto e meio salário mínimo, distribuições que evidenciam que a população de mais baixa renda e negra são, de fato, SUS-dependentes.

A Atenção Básica $(\mathrm{AB})$ é a porta de entrada para o Sistema Único de Saúde e é considerada a ordenadora do cuidado, devendo estar próxima da vida das pessoas em todas as fases de desenvolvimento, e ser o contato preferencial dos usuários com o sistema de saúde. Para Starfield (2002), a AB é orientada segundo os seguintes princípios: acesso de primeiro contato, longitudinalidade, coordenação do cuidado, integralidade, abordagem familiar e enfoque comunitário.

Dessa forma, reafirmando-se que o racismo produz efeitos deletérios na saúde da população negra, considera-se como atribuição da Atenção Básica ofertar cuidado pautado na integralidade das ações e serviços para combater as iniquidades vivenciadas por esse grupo, por meio de ações em conjunto com suas equipes e com a população, visando, dentre outros, a promoção, prevenção, proteção, redução de danos e cuidado integrado, conforme preconiza a Política Nacional de Atenção Básica (BRASIL, 2017b).

\section{Iniquidades em saúde e racismo}

A produção de material científico que aborde a relação entre racismo e saúde da população negra ainda se mostra insuficiente, diante da complexidade dessa questão. No entanto, dados já demonstram como o racismo se configura enquanto iniquidade no campo da saúde. Nesse campo, as manifestações do racismo 
estão presentes em diversas situações, desde a formação de profissionais de saúde, que ainda não aborda essa questão da forma como é preconizado na Política Nacional de Saúde Integral da População Negra, até os atendimentos realizados à população, que podem ser marcados por tratamento desumanizante e pelo não reconhecimento das particularidades concernentes à saúde da população negra.

Além disso, as condições socioeconômicas precárias nas quais grande parte da população negra se concentra também se constitui enquanto determinante em saúde. Oliveira e Kubiak (2019) afirmam que a população negra apresenta os piores indicadores sociais, menor nível de escolaridade e renda, menor acesso à saúde e serviços sociais, condições precárias de moradia e está inserida nas piores posições de trabalho.

Ademais, essa população, devido à sua condição de marginalização, está mais exposta a situações de violência, que também afetam sua condição de saúde. Segundo Cerqueira e Moura (2013), tal fato é atribuído a fatores históricos como a escravidão e o período pós-abolição, quando não foram oferecidas aos escravizados condições objetivas para exercer sua liberdade.

Segundo os autores, uma das heranças das discriminações raciais e econômicas contra a população negra no Brasil é a letalidade violenta, devido aos menores níveis educacionais, maiores dificuldades de acesso à justiça e mecanismos de solução de conflitos, menor acesso a mecanismos de proteção e menor flexibilidade para residir e frequentar lugares menos violentos. Além disso, os autores ressaltam que a perpetuação de estereótipos sobre o papel do negro na sociedade muitas vezes os associa a indivíduos perigosos ou criminosos, o que pode aumentar a probabilidade de vitimização desses indivíduos, inclusive pelas forças policiais.

Oliveira e Kubiak (2019) analisam produções científicas que abordam os impactos do racismo institucional para a saúde da população negra, com enfoque para a saúde da mulher negra. As autoras afirmam que a falta de conhecimento sobre doenças predominantemente negras, como a anemia falciforme, por exemplo, acarreta como consequência seu diagnóstico tardio e sofrimento para quem porta a doença. Além disso, segundo as autoras, o racismo institucional se manifesta, no âmbito da saúde, no tratamento oferecido à população negra, tendo em vista que ainda ocorre a reprodução de estereótipos como o de que pessoas negras são mais resistentes à dor ou que não adoecem, que tendem a minimizar queixas advindas de pessoas negras e restringir seu acesso a medicamentos e anestesias, principalmente se tratando de mulheres nas consultas de pré-natal e durante o parto.

As autoras revelam que mulheres negras possuem menor expectativa de vida e maior índice de morte por transtornos mentais do que mulheres brancas; apresentam prevalência e reincidência de miomas uterinos e taxa elevada de mortalidade materna, além de serem mais sujeitas à violência obstétrica.

Werneck (2016, p. 537) afirma que no processo de formulação da Política Nacional de Saúde Integral da População Negra foram classificadas as doenças, agravos e condições mais frequentes na população negra, sintetizadas a seguir:

a) Por fatores genéticos: anemia falciforme e deficiência de glicose 6-fosfato desidrogenase, hipertensão arterial e diabete melito;

b) Adquiridas, derivadas de condições socioeconômicas desfavoráveis: desnutrição, mortes violentas, mortalidade infantil elevada, abortos sépticos, anemia ferropriva, DST/AIDS, doenças do trabalho, transtornos mentais resultantes da exposição ao racismo e ainda transtornos derivados do abuso de substâncias psicoativas, como o alcoolismo e a toxicomania.

c) De evolução agravada ou de tratamento dificultado: hipertensão arterial, diabete melito, coronariopatias, insuficiência renal crônica, câncer e mioma.

d) Condições fisiológicas alteradas por condições socioeconômicas: crescimento, gravidez, parto e envelhecimento.

Analisando os efeitos do racismo sobre as internações e mortes em decorrência da pandemia ocasionada pelo vírus Sars-CoV (COVID-19), Oliveira et al. (2020) trabalham com o conceito de necropolítica, que tem sido utilizado para compreender a relação entre Estado e um padrão de genocídio de populações racializadas. Trata-se do direito de deixar morrer ou de matar, em nome da sustentação de determinados modos de reprodução de outras vidas consideradas mais legítimas. Segundo os autores, a realidade da classe trabalhadora de baixa renda, majoritariamente negra e moradora de territórios vulnerabilizados, deixa essa população mais exposta à infecção e complicações de saúde devido à COVID-19.

São predominantemente trabalhadores precarizados, que não possuem o privilégio de ficar em casa, em regime de trabalho remoto; que utilizam os transportes públicos superlotados; têm acesso precário ao 
saneamento básico; e estão na linha de frente do atendimento ao público no setor de serviços, incluindo os de saúde. (OLIVEIRA et al., 2020, p. 2).

Nesse sentido, as estatísticas sobre as mortes por COVID-19 revelam que há uma discrepância demarcada por fatores étnico-raciais. Oliveira et al. (2020) afirmam que na cidade de Chicago, Estados Unidos, por exemplo, a população negra representa $29 \%$ da população total, porém, correspondeu, até a primeira semana de abril, a 70\% das mortes por COVID-19. No Brasil, os autores revelam que no início da pandemia a proporção de internações entre a população branca era de $73 \%$, e de $23,9 \%$ entre a população negra, mas, no período seguinte, a tendência de hospitalização entre a população negra aumentou para 49\%. Já a taxa de óbitos é muito maior entre a população negra, alcançando uma margem de 57\% de mortes de pessoas negras e 34,3\% de mortes de pessoas brancas. Para os autores, a população negra enfrenta sérias barreiras de acesso aos serviços de saúde e condições precárias de moradia e trabalho, que os colocam às margens das ações de saúde e que marca sua presença massiva no número de óbitos, o que se configura enquanto um mecanismo de necropolítica.

Werneck (2016) afirma que as reivindicações da população negra e de movimentos sociais por melhor acesso ao sistema de saúde se intensificaram na segunda metade do século XX, culminando na criação do Sistema Único de Saúde. No entanto, a autora revela que a presença do movimento negro junto ao movimento de Reforma sanitária não foi suficiente para inserir, nesse novo sistema de saúde, mecanismos explícitos de superação das barreiras enfrentadas pela população negra no acesso à saúde, principalmente aquelas interpostas pelo racismo.

Uma política de saúde que se pretenda universal, e que tenha como um de seus princípios a equidade, necessita qualificar suas ações no sentido de atender as demandas de populações socialmente marginalizadas, e que têm seu acesso aos serviços restrito devido às condições de vida e à forma como são tratadas nos estabelecimentos de saúde. Nesse sentido, uma das medidas a serem tomadas é o investimento na qualificação de profissionais de saúde no que se refere a questões específicas sobre a saúde da população negra, que acessa de forma majoritária o SUS.

\section{A PNSIPN e a formação dos profissionais de saúde}

Não é possível abordar a discussão sobre racismo institucional e a forma como ele se manifesta no campo da saúde sem que se compreenda como a formação de profissionais de saúde afeta a qualidade do cuidado dessa população. De acordo com Barros et al. (2020), a formação dos profissionais de saúde na atualidade está fundamentada no esforço mundial por elevar os patamares de saúde das populações, devendo o Estado assegurar o direito à saúde, e o Ministério da Saúde ordenar a formação de profissionais da área.

Nesse sentido, no que tange à formação de profissionais que reconheçam o racismo enquanto produtor de iniquidades em saúde, esta ainda se mostra deficitária, apresentando pouco espaço para discussões acerca das desigualdades étnico-raciais em nosso País e a forma como elas afetam os processos de saúde e adoecimento, o que perpetua, entre os profissionais, a invisibilização ou minimização dos efeitos do racismo. É nesse contexto que, em 2009, foi aprovada a Política Nacional de Saúde Integral da População Negra (PNSIPN), que se configura, segundo o documento, enquanto

[...] compromisso firmado pelo Ministério da Saúde no combate às desigualdades no Sistema Único de Saúde (SUS) e na promoção da saúde da população negra de forma integral, considerando que as iniquidades em saúde são resultados de injustos processos socioeconômicos e culturais — em destaque, o vigente racismo - que corroboram com a morbimortalidade das populações negras brasileiras. (BRASIL, 2017a).

Essa política visa instrumentalizar gestores, movimentos sociais, conselheiros e profissionais do SUS no combate ao racismo institucional e melhoria das condições de saúde da população negra, reconhecendo o racismo como determinante social em saúde. O documento traz dados importantes acerca dos perfis social e econômico da população negra no Brasil e seu acesso aos serviços de saúde.

Corroborando o supracitado, sobre a educação deficitária de profissionais de saúde no que tange à saúde da população negra e às formas de enfrentamento do racismo institucional, a referida política afirma que, em 2013, 10,6\% das pessoas que utilizaram o SUS afirmaram que já se sentiram discriminadas ou tratadas de 
maneira pior que as outras pessoas no serviço de saúde, por médico ou profissional de saúde. Dessas, 11,6\% eram mulheres, $23 \%$ eram pessoas negras e 11,8\% eram pessoas sem instrução ou com ensino fundamental incompleto (BRASIL, 2017a).

Torna-se então imperativo investir, dentre outras medidas, na formação de profisssionais de saúde, visando a eliminação dessas práticas e a qualificação do cuidado. Tendo em vista seu caráter informativo e crítico, o projeto ECOS se configura enquanto processo de formação em saúde, atendendo às diretrizes I e IV da referida política (BRASIL, 2017a):

I - inclusão dos temas Racismo e Saúde da População Negra nos processos de formação e educação permanente dos trabalhadores da saúde;

IV - desenvolvimento de processos de informação, comunicação e educação que desconstruam estigmas e preconceitos, fortaleçam uma identidade negra positiva e contribuam para a redução de vulnerabilidades.

Ademais, tendo em vista que o projeto se originou da percepção de situações de racismo vivenciadas por profissionais negros, o projeto visa cumprir também o objetivo específico IV dessa política (BRASIL, 2017a): "IV - identificar, combater e prevenir situações de abuso, exploração e violência, incluindo assédio moral, no ambiente de trabalho".

A expectativa é a de que a exposição tenha sido apenas o primeiro de muitos momentos que o projeto promoverá, suscitando debates e promovendo conhecimentos sobre racismo e saúde da população negra, tendo em vista que o ECOS foi concebido enquanto projeto com ações recorrentes, tanto dentro da UBS na qual ele se originou, quanto em outras que se demonstrem abertas para as ações do projeto.

\section{ECOS: consciência, cor e saúde}

O projeto ECOS: consciência, cor e saúde foi idealizado pelos residentes do programa de Atenção Básica da FIOCRUZ, sendo eles, uma assistente social, uma nutricionista e um fisioterapeuta, e projetado juntamente com a equipe do NASF atuantes em uma UBS da região oeste do Distrito Federal. Cabe ressaltar que os três residentes e a assistente social da equipe, que estiveram à frente do projeto, se identificam como negros, o que foi interpretado como importante fator de impulsionamento do projeto, tendo em vista que o racismo afeta não apenas o indivíduo que sofre, mas toda a comunidade ao seu redor. Entende-se que quando uma voz é silenciada diante de situações de racismo, as vozes de outras pessoas negras também são, portanto, o projeto ECOS surge da necessidade de fazer com que nossas vozes ecoem juntas no combate ao racismo e na produção de uma formação em saúde pautada na integralidade dos sujeitos. A definição do projeto escrito pelos residentes ressalta que: "ecoar significa produzir eco, fazer refletir um som. Encontrar eco é receber apoio, acolhida e receptividade" (OLIVEIRA-COSTA, 2020).

Faz parte das funções do NASF, de acordo com a PNAB (2017), prestar contribuição no processo de educação permanente das equipes de seu local de atuação, buscando qualificar o trabalho exercido e elevar o cuidado prestado. Tratando-se de um campo de atuação em uma região com predominância da população negra, conhecer dados pertinentes ao cuidado a esse grupo demográfico é de extrema relevância para um atendimento qualificado.

O projeto ECOS foi elaborado a partir da percepção de que ocorriam situações explícitas e camufladas de racismo ocorrendo na dinâmica da instituição na qual ele foi implementado. Como já foi ressaltado, a dimensão estrutural do racismo não viabiliza que ele seja extinto apenas com a presença de sujeitos negros nas instituições. Nesse sentido, apesar da presença de profissionais negros atuando na equipe da referida unidade de saúde, foram relatadas situações de constrangimentos e discriminação, especialmente na relação entre os próprios profissionais. Sendo assim, apesar de terem a mesma formação profissional, por exemplo, foram feitos relatos em que a capacidade de profissionais negros era questionada, apenas com base em suas características fenotípicas, além de situações mais explícitas, como a recusa em se aproximar de profissionais negros e o uso de expressões racistas, como "o que essa neguinha está fazendo aqui?", por exemplo. A situação se agravou a ponto de uma das vítimas solicitar remoção para outro local de trabalho, visando resguardar sua saúde psíquica. 
A primeira intervenção elaborada pela equipe do NASF foi o estímulo à denúncia, tendo em vista que o racismo está tipificado como crime na Lei n ${ }^{\circ} 7.716 / 89$ e no Código Penal Brasileiro (BRASIL, 1989). No entanto, diante de dificuldades das vítimas em realizar a denúncia, ela não foi possibilitada, e os agressores não foram identificados. Santos (2015) revela que o sistema judiciário brasileiro apresenta um padrão de pouco reconhecimento de crimes raciais, demonstrando a insensibilidade diante das queixas feitas pelas vítimas negras e a inoperância do sistema de justiça na punição do racismo. A autora aponta que, por isso, as vítimas não parecem acreditar que a lei seja capaz de cuidar de seus casos.

Tendo em vista que o racismo se constitui de maneira estrutural, e se manifesta na realidade das instituições, é dever ético dos profissionais de saúde intervir nessa questão, que se configura enquanto elemento de marginalização da população negra, atingindo, inclusive, profissionais de saúde. Sendo assim, foi idealizada uma exposição dentro da instituição, para que fossem problematizados, de maneira lúdica, criativa e interativa, dados sobre o racismo no Brasil e seus reflexos nas relações individuais, sociais e profissionais. Inicialmente foi planejada a elaboração de uma carta de repúdio às situações ocorridas, porém, apenas a carta foi considerada insuficiente, devido à gravidade e dimensão da situação. Foi elaborado então, pela residência em Atenção Básica da Fiocruz, o projeto ECOS, que em conjunto com a equipe NASF visava expor o racismo enquanto questão que estava, ao mesmo tempo, aparente e invisibilizada, e as vulnerabilidades por ele causadas.

Objetivando estimular o engajamento do maior número de profissionais no evento, ele foi formulado no formato de exposição. Importante ressaltar que todo o processo foi informado às vítimas, que foram convidadas a participar de acordo com suas possibilidades. O principal desafio dessa ação esteve relacionado às medidas de contingência, devido ao fato de que estamos atravessando um período de pandemia causada pela COVID-19. Como solução, a exposição foi planejada em um ambiente externo e aberto da UBS, visando respeitar as medidas de biossegurança. A ação foi dividida em pelo menos cinco etapas.

A primeira etapa foi o levantamento de dados sobre racismo, retirados de pesquisas empíricas e levantamentos feitos por órgãos oficiais, tais como o Instituto Brasileiro de Geografia e Estatística (IBGE) e o Instituto de Pesquisa Econômica Aplicada (IPEA), com especial enfoque na saúde, trabalho, educação, violência, gênero e território da região oeste. A segunda etapa foi a sistematização desses dados e tradução dos mesmos em imagens para a exposição. Na terceira etapa foi realizada uma reunião de alinhamento com o NASF, visando iniciar a discussão dentro dessa equipe, antes de levá-la às equipes de saúde da família. Nessa mesma reunião foram apresentados os dados que seriam utilizados na exposição.

Após esse período, foi iniciada a quarta etapa, de compra de materiais, feitas impressões em gráficas e a produção de lembrancinhas para os participantes do evento. Essas foram pensadas como lembretes às equipes de que esse debate não se esgotaria com a exposição. A primeira lembrancinha escolhida foi um cacto, representando resistência e florescimento, conforme explicita o texto que foi entregue aos participantes junto com ele:

O cacto simboliza resistência, força e adaptação. É capaz de sobreviver em ecossistemas muito áridos e quentes, e em terrenos difíceis, dispondo de uma resistência que poucas plantas possuem. As flores dos cactos simbolizam perseverança e firmeza, mas para que possam florescer é necessário que eles sejam bem cuidados e que o clima seja ideal.

Nesse texto, foi feita uma analogia entre o cacto e a população negra do nosso País, em especial a da região oeste do DF: apesar de todos os indicadores comprovarem a desigualdade e condições desfavoráveis nas quais essa população se encontra, ela resiste, se recria, e floresce. Esperávamos que essa lembrancinha servisse de inspiração e nos despertasse para a criação de um ambiente de proteção, cuidado e de firmeza no combate à discriminação. Atualmente, ainda é possível observar que algumas equipes cuidam e mantém os cactos em suas salas de atendimento.

A segunda lembrancinha foi distribuída em caixas contendo ervas para o preparo de chás. Nelas, explicamos que os chás faziam parte da tradição iorubá, e que são parte de um processo de autocuidado e ancestralidade:

A etnia iorubá é parte significativa da história do continente africano, tendo muita influência também na cultura brasileira. É uma das maiores etnias africanas, sendo oriunda do sudoeste da Nigéria e sul do Benin. A tradição oral tem um peso sagrado para a cultura iorubá, permitindo que as gerações transmitam sua herança ancestral e preservando sua cultura. 
A quinta etapa foi a elaboração de uma carta de repúdio, que denunciava as situações de racismo ocorridas, e junto com ela, foi elaborada uma carta de compromissos, que seria assinada por aqueles que comparecessem à exposição, e que se comprometeriam a adotar práticas de combate ao racismo no ambiente de trabalho. A carta de compromisso foi assinada por todos os profissionais que compareceram ao evento, e posteriormente, foi afixada em um local visível na UBS. Os itens descritos na carta estão listados a seguir:

I. Estimular a promoção da diversidade e da equidade racial nas minhas práticas profissionais;

II. Influenciar políticas públicas em um esforço coletivo para superar a discriminação racial;

III. Incluir os temas Racismo e Saúde da População Negra nos processos de formação e educação permanente junto aos meus colegas de equipe, visando prevenir e erradicar toda forma de discriminação e promover a equidade no local de trabalho;

IV. Promover uma cultura de tolerância zero à discriminação racial e de gênero e de incentivo à equidade nas relações entre profissionais de saúde e no trato com os usuários do serviço;

V. Qualificar a coleta, o processamento e a análise dos dados desagregados por raça/cor, bem como nas informações epidemiológicas divulgadas anualmente pelo SUS, respeitando o direito à autoidentificação dos sujeitos.

Previamente, foram feitos convites às equipes da UBS de forma presencial e, também, por meio de grupos de mensagens eletrônicas, utilizando, para tanto, um vídeo produzido por uma profissional de nutrição do NASF. O evento ocorreu em julho de 2020, no período da tarde, e contou com a presença de 55 pessoas, entre profissionais da saúde das diversas categorias, residentes, servidores da limpeza, vigilantes, entre outros.

A organização do ambiente levou em conta o espaço aberto, que era amplo, para que as informações fossem expostas no formato de um varal. Os dados foram apresentados em conjunto com poesias, músicas e fotografias que ressaltam a riqueza da cultura afro-brasileira. Foram montadas mesas onde estavam expostos também livros com temáticas pertinentes ao evento, bonecas negras, ressaltando a importância de trabalhar essa temática desde a infância, e em uma das mesas era explicado sobre a importância da assinatura da carta de compromissos. A leitura da carta de repúdio foi feita pela vítima que compareceu no evento. Sua participação nesse momento foi de fundamental importância para que se compreendesse os efeitos que o racismo causa em suas vítimas, tendo em vista que a mesma detalhou as situações vivenciadas, os sentimentos aflorados e a importância do evento diante de situações como essa.

Para finalizar o evento, o projeto ECOS preparou um sorteio para as pessoas que compareceram e o resultado foi divulgado no perfil da rede social Instagram (@ecos.e.cor.saude), criado com intuito de divulgar o evento e dar maior visibilidade aos dados que foram levantados e apresentados na exposição, além de ser um canal utilizado para divulgação de novas ações e projetos. Foram sorteados dois livros da autora Djamila Ribeiro com o título Pequeno manual antirracista, que trata de temas como racismo, negritude, branquitude, violência racial e cultura. Em outubro, na semana do Dia das Crianças, o projeto realizou um novo sorteio e o objeto sorteado foi uma boneca Barbie negra, doada ao projeto por uma assistente social do NASF para esse propósito.

Como forma de dar continuidade ao projeto, será realizada a produção de um vídeo com a temática do racismo e saúde da população negra, que contará com o protagonismo de profissionais e residentes negros da UBS. Os participantes poderão falar de como a temática do racismo é trabalhada na formação profissional, a importância dessa temática na saúde, relatos de racismo sofridos no ambiente de trabalho e recitar poemas ou músicas. Além disso, tendo em vista que o ECOS foi projetado com o objetivo de desenvolver ações contínuas, pretende-se que, com o retorno de atividades coletivas após as medidas de contingência ocasionadas pela pandemia de Covid-19, o projeto seja levado para outras unidades de saúde, especialmente da região oeste do Distrito Federal, e também para espaços comunitários dentro da região de atuação da unidade de saúde na qual o projeto se originou. 


\section{Considerações finais}

A compreensão da dinâmica e efeitos ocasionados pelo racismo no campo da saúde demanda ações conjuntas no sentido de qualificar as intervenções dos serviços de saúde, no combate às iniquidades oriundas do acesso deficitário e do tratamento desigual, ocasionado por preconceitos e estereótipos raciais. Se os próprios profissionais negros, com formação de nível superior e melhores condições socioeconômicas estão sujeitos a situações de racismo no ambiente de trabalho, os usuários negros dos serviços, conforme constatou-se através dos dados apresentados, estão sujeitos a situações semelhantes ou mesmo piores, que podem ser agravadas devido ao baixo grau de instrução e classe socioeconômica aos quais pertencem a maior parte dos usuários do SUS.

Nesse sentido, ações educativas que abordem o combate à discriminação racial, como o projeto ECOS, se configuram enquanto importantes instrumentos, que têm a finalidade de romper ciclos de violência racial, tanto na relação entre profissionais, quanto na relação destes com os usuários dos serviços de saúde.

Compreende-se, no entanto, que o racismo estrutural exige que o conjunto da sociedade, através de políticas de Estado, fomente ações que extrapolem a dimensão individual e, também, institucional dessa questão. Sendo assim, para além da qualificação de profissionais de saúde, é necessário o investimento nas políticas educacionais, sociais, habitacionais, de segurança e de trabalho, visando dirimir as desigualdades e vulnerabilidades que localizam a população negra brasileira, em sua maioria, em posições socialmente marginalizadas.

Importante salientar que o envolvimento de diversas categorias profissionais nesse processo, como foi possível observar na execução das ações do projeto ECOS até o momento, demonstra que o compromisso com a eliminação de práticas discriminatórias na saúde é papel de todos os profissionais que atuam no Sistema Único de Saúde, especialmente daqueles que atuam junto à uma população majoritariamente negra, como na região oeste do Distrito Federal.

\section{Referências}

ALMEIDA, M. da S. Desumanização da população negra: genocídio como princípio tácito do capitalismo. Revista da Faculdade de Serviço Social da Universidade do Estado do Rio de Janeiro, Rio de Janeiro, n. 34, p. 131-154, 2014. Disponível em: https://www.epublicacoes.uerj.br/index.php/revistaempauta/article/view/15086/0. Acesso em: 12 out. 2021.

ALMEIDA, M. da S. Diversidade humana e racismo: notas para um debate radical no Serviço Social. Argumentum, Espírito Santo, v. 9, n. 1, p. 32-45, 2017. Disponível em: https://periodicos.ufes.br/argumentum/article/view/15764. Acesso em: 15 set. 2021.

ALMEIDA, S. Racismo estrutural. São Paulo: Pólen Produção Editorial, 2019.

BARROS, R. et al. Movimentos sociais em luta contra o racismo de Estado e pela vida: contribuições ao debate sobre saúde. Saúde em Debate, Rio de Janeiro, v. 43, p. 324-337, 2020. DOI https://doi.org/10.1590/0103-11042019s823. Disponível em: https://www. scielo.br/scielo.php?pid=S0103-11042019001300324\&script=sci_abstract\&tlng =pt. Acesso em: 15 set. 2021.

BRASIL. Lei $n^{\circ}$ 7.716, de 5 de janeiro de 1989. Define crimes resultantes de preconceito de raça ou de cor. Brasília, DF: Presidência da República, 1989. Disponível em: http://www.planalto.gov.br/ccivil_03/leis/17716.htm. Acesso em: 24 dez. 2020.

BRASIL. Ministério da Saúde. Política Nacional de Saúde Integral da População Negra: uma política para o SUS. 3. ed. Brasília, 2017a. BRASIL. Ministério da Saúde. Portaria no 2.436 de 2017. Política Nacional de Atenção Básica. Brasília, 2017 b.

CERQUEIRA, D. et al. Atlas da violência 2020. Instituto de Pesquisas Econômicas Aplicadas (IPEA), Brasília, DF: Ministério da Economia, 2020.

CERQUEIRA, D. R. C.; MOURA, R. L. DE. Vidas perdidas e racismo no Brasil. Brasília: IPEA, 2013. (Nota técnica n 10).

CHAUÍ, M. Convite à filosofia. São Paulo: Ática, 1995.

GELEDÉS - INSTITUTO DA MULHER NEGRA et al. Guia de enfrentamento do racismo institucional. 2013. Disponível em <http:// www.geledes.org.br>

INSTITUTO DE PESQUISA ECONÔMICA APLICADA (IPEA). Retrato das desigualdades de gênero e raça. 4. ed. Brasília: Ipea, 2011. Disponível em: https://www.ipea.gov.br/retrato/pdf/revista.pdf. Acesso em: 15 set. 2020.

KRUG, E. G. et al. Relatório Mundial sobre Violência e Saúde. Genebra: Organização Mundial de Saúde, 2002.

MINAYO, M. C. de S. A difícil e lenta entrada da violência na agenda do setor saúde. Cad. Saúde Pública, Rio de Janeiro, v. 20, n. 3, p. 646-647, jun. 2004. 
OLIVEIRA, B. M. C.; KUBIAK, F. Racismo institucional e a saúde da mulher negra: uma análise da produção científica brasileira. Saúde em Debate, v. 43, p. 939-948, 2019. Disponível em: https://www.scielo.br/scielo.php?pid=S0103-11042019000300939\&script=sci_ abstract\&tlng=pt. Acesso em: 21 set. 2020.

OLIVEIRA, R. G. DE et al. Desigualdades raciais e a morte como horizonte: considerações sobre a COVID-19 e o racismo estrutural. Cadernos de Saúde Pública, Rio de Janeiro, v. 36, n. 9, 2020. DOI https://doi.org/10.1590/0102-311x00150120. Disponível em: https:// www.scielo.br/scielo.php?pid=S0102-311X2020000903003\&script=sci_arttext. Acesso em: 21 set. 2020.

OLIVEIRA-COSTA, M. Alunos da Fiocruz Brasília promovem ações sobre o racismo no SUS. Fiocruz, Brasília: DF, jul. 2020. Não paginado.

SANTOS, G. A. dos. Nem crime, nem castigo: o racismo na percepção do judiciário e das vítimas de atos de discriminação. Revista do Instituto de Estudos Brasileiros, n. 62, p. 184-207, 2015. Disponível em: https://www.scielo.br/pdf/rieb/n62/2316-901X-rieb-62-00184. pdf. Acesso em: 10 out. 2020.

STARFIELD, B. Atenção primária: equilíbrio entre necessidades de saúde, serviços e tecnologia. Brasília: UNESCO; Ministério da Saúde, 2002.

WERNECK, J. Racismo institucional e saúde da população negra. Saúde e Sociedade, v. 25, p. 535-549, 2016. Disponível em: https:// www.scielo.br/pdf/sausoc/v25n3/1984-0470-sausoc-25-03-00535.pdf. Acesso em: 10 out. 2020.

\section{Raquel Rodrigues da Silva Barbosa}

raquelrsilvabarbosa@gmail.com

Assistente Social (Universidade de Brasília - UnB, Brasília, Distrito Federal), especialista em Saúde Mental do Adulto (Escola Superior de Ciências da Saúde - ESCS, Brasília, Distrito Federal)

Residente do Programa de Residência em Atenção Básica (Escola FIOCRUZ de Governo - EFG, Brasília, Distrito Federal)

\section{Cristiane Souza da Silva}

criisouzasilva@gmail.com

Nutricionista (Centro Universitário Unieuro, Brasília, Distrito Federal)

Residente do Programa de Residência em Atenção Básica (Escola FIOCRUZ de Governo - EFG, Brasília, Distrito Federal)

\section{Arthur Alves Pereira Sousa}

Arthursousa560@gmail.com

Fisioterapeuta (Universidade Paulista - UNIP, Brasília, Distrito Federal)

Residente do Programa de Residência em Atenção Básica (Escola FIOCRUZ de Governo - EFG, Brasília, Distrito Federal)

\section{FIOCRUZ Brasília}

Avenida L3 Norte, s/n, Campus Universitário Darcy Ribeiro, Gleba A

Brasília - Distrito Federal, Brasil

CEP 70904-130

\section{Agradecimentos}

Agradecemos a todas as pessoas que colaboraram na elaboração e implementação do projeto ECOS, em especial a enfermeira Samara Rodrigues da Silva, a assistente social Cibele Maria de Sousa e toda a equipe do Núcleo Ampliado de Saúde da Família da Unidade Básica de Saúde da região oeste, onde o projeto foi realizado.

Agência financiadora

Não se aplica.
Contribuições das autoras

Não se aplica.

Aprovação por Comitê de Ética e consentimento para participação

Não se aplica.

Consentimento para publicação

Consentimento dos autores.

Conflito de interesses

Não há conflito de interesses. 